\title{
Wean Earlier and Automatically with New technology (the WEAN study): a protocol of a multicentre, pilot randomized controlled trial
}

\author{
Karen EA Burns*1,2, Maureen O Meade ${ }^{3}$, Martin R Lessard ${ }^{4}$, Sean P Keenan ${ }^{5}$ \\ and Francois Lellouche ${ }^{6}$
}

Address: ${ }^{1}$ Interdepartmental Division of Critical Care Medicine, University of Toronto, Toronto, Ontario, Canada, ${ }^{2}$ Keenan Research Centre and the Li Ka Shing Knowledge Institute, St. Michael's Hospital, Toronto, Ontario, Canada, ${ }^{3}$ Department of Clinical Epidemiology and Biostatistics, McMaster University, Hamilton, Ontario, Canada, ${ }^{4}$ Divisions of Anesthesia and Critical Care, Hôpital de l'Enfant-Jésus, Université Laval Quebec City, Quebec, Canada, ${ }^{5}$ Division of Critical Care, Royal Columbian Hospital, New Westminster, B.C., Canada and ${ }^{6}$ Division of Critical Care, Hopital Laval, Quebec City, Quebec, Canada

Email: Karen EA Burns* - burnsk@smh.toronto.on.ca; Maureen O Meade - meadema@HHSC.ca; Martin R Lessard - mrlessard@videotron.ca; Sean P Keenan - sean_keenan@telus.net; Francois Lellouche - francois.lellouche@free.fr

* Corresponding author

Published: 4 September 2009

Trials 2009, 10:81 doi:10.1186/1745-62/5-10-81
Received: 23 June 2009

Accepted: 4 September 2009

This article is available from: http://www.trialsjournal.com/content/I0/I/8I

(C) 2009 Burns et al; licensee BioMed Central Ltd.

This is an Open Access article distributed under the terms of the Creative Commons Attribution License (http://creativecommons.org/licenses/by/2.0), which permits unrestricted use, distribution, and reproduction in any medium, provided the original work is properly cited.

\begin{abstract}
Background: Weaning is the process during which mechanical ventilation is withdrawn and the work of breathing is transferred from the ventilator back to the patient. Prolonged weaning is associated with development of ventilator-related complications and longer stays in the Intensive Care Unit (ICU). Computerized or Automated Weaning is a novel weaning strategy that continuously measures and adapts ventilator support (by frequently measuring and averaging three breathing parameters) and automatically conducts Spontaneous Breathing Trials to ascertain whether patients can resume autonomous breathing. Automated Weaning holds promise as a strategy to reduce the time spent on the ventilator, decrease ICU length of stay, and improve clinically important outcomes.

Methods/Design: A pilot weaning randomized controlled trial (RCT) is underway in the ICUs of 8 Canadian hospitals. We will randomize 90 critically ill adults requiring invasive ventilation for at least 24 hours and identified at an early stage of the weaning process to either Automated Weaning (SmartCare ${ }^{\mathrm{TM}}$ ) or Protocolized Weaning. The results of a National Weaning Survey informed the design of the Protocolized Weaning arm. Both weaning protocols are operationalized in Pressure Support mode, include opportunities for Spontaneous Breathing Trials, and share a common sedation protocol, oxygen titration parameters, and extubation and reintubation criteria. The primary outcome of the WEAN study is to evaluate compliance with the proposed weaning and sedation protocols. A key secondary outcome of the pilot RCT is to evaluate clinician acceptance of the weaning and sedation protocols. Prior to initiating the WEAN Study, we conducted a run-in phase, involving two patients per centre (randomizing the first participant to either weaning strategy and assigning the second patient to the alternate strategy) to ensure that participating centres could implement the weaning and sedation protocols and complete the detailed case report forms.
\end{abstract}

Discussion: Mechanical ventilation studies are difficult to implement; requiring protocols to be operationalized continuously and entailing detailed daily data collection. As the first multicentre weaning RCT in Canada, the WEAN Study seeks to determine the feasibility of conducting a large scale future weaning trial and to establish a collaborative network of ICU clinicians dedicated to advancing the science of weaning.

Trial Registration Number: ISRCTN43760I5I 


\section{Background}

Weaning is the process during which mechanical ventilation is gradually or abruptly withdrawn. In addition, it is the time during which work of breathing is transferred from the ventilator back to the patient until fully autonomous breathing is resumed. Weaning accounts for approximately $40 \%$ of the total time spent on mechanical ventilation $[1,2]$. Invasive mechanical ventilation is associated with the development of important complications including ventilator associated pneumonia (VAP) [3], sinusitis [4], upper airway pathology [3] and respiratory muscle weakness [3]). VAP, in turn, is associated with increased morbidity and a trend toward increased mortality [5]. Mechanical ventilation has recently been identified as a key factor escalating intensive care unit (ICU) costs [6]. For these reasons, minimizing exposure to prolonged ventilation is an important goal of critical care medicine [7].

Over the past decade, research has focused on strategies to limit the duration of ventilation through early identification of weaning candidates $[8,10]$, the conduct of tests of readiness to resume autonomous breathing [spontaneous breathing trials (SBTs)] $[11,13]$ and strategies to reduce support in patients who fail a SBT $[14,16]$. Several modes and techniques are used to facilitate weaning. The optimal strategy to wean patients from invasive ventilation remains unclear. Compared to traditional care, protocols with their requirement for scheduled surveillance generally decrease the time to discontinuation and total duration of mechanical support [8-10]. Despite demonstration of large-scale implementation, many barriers exist to implementing weaning protocols in clinical practice including the requirement for broad, educational interventions and multidisciplinary compliance with them $[17,18]$.

Automated weaning systems use closed-loop control to interpret clinical data in real time, perform basic and advanced ventilator functions and enable interaction between patients and the ventilator. Closed-loop systems adapt ventilator output by comparing measured values to targeted values of selected respiratory parameters and either minimizing or equilibrating (negative feedback) or amplifying (positive feedback) the differences between these values [19]. SmartCare ${ }^{\mathrm{TM}}$ is a unique automated system, specifically designed to guide weaning, that incorporates a closed-loop knowledge based system [20,21] into an automated protocol that adapts the level of pressure support provided to individual patient needs by operationalizing predetermined algorithms based upon respiratory rate $(\mathrm{RR})$, tidal volume $\left(\mathrm{V}_{\mathrm{T}}\right)$ and end-tidal carbon dioxide $\left(\mathrm{ETCO}_{2}\right)$.

To initiate SmartCare ${ }^{\mathrm{TM}}$ end-users enter the patient's weight, the presence or absence of chronic obstructive pulmonary disease (COPD) or a central neurologic disorder, type of airway prosthesis (tracheostomy or oro/nasal endotracheal tube) and the type of humidification (heated humidification or heat and moisture exchanger) in use. The first three parameters establish limits for $R R, V_{T}$ and $\mathrm{P}_{\mathrm{ET}} \mathrm{CO}_{2}$ and the latter two items determine the threshold to cycle into a SBT (range: 5 to $12 \mathrm{~cm} \mathrm{H}_{2} \mathrm{O}$ ). SmartCare $^{\mathrm{TM}}$ categorizes patients into one of 8 diagnostic categories based on average measurements of these parameters made every 2 to 5 minutes. With SmartCare ${ }^{\mathrm{TM}}$, patients may breathe with a RR ranging from 15 to 30 breaths/min (RR min) (alternatively, 34 breaths/min with neurologic disease) ( $R R$ max), a $V_{T}$ above a minimum threshold $\left(\mathrm{V}_{\mathrm{T}}\right.$ Min $=250 \mathrm{ml}$ if weight $<55 \mathrm{~kg}$, or $\mathrm{V}_{\mathrm{T}}$ Min = $300 \mathrm{ml}$ if weight $\geq 55 \mathrm{~kg}$ ) and a $\mathrm{P}_{\mathrm{ET}} \mathrm{CO}_{2}$ below a maximum threshold ( $\max \mathrm{P}_{\mathrm{ET}} \mathrm{CO}_{2}=55 \mathrm{mmHg}$ or $\max \mathrm{P}_{\mathrm{ET}} \mathrm{CO}_{2}=65$ $\mathrm{mmHg}$ for COPD patients). SmartCare ${ }^{\mathrm{TM}}$ diagnosis a state of normal ventilation when a patient's ventilatory parameters fall within these ranges. If patient parameters fall outside of these ranges, an alternate diagnosis is made and the system adjusts the level of pressure support provided to attain these targets.

SmartCare ${ }^{\mathrm{TM}}$ automatically initiates a SBT when predetermined thresholds of pressure support are reached [22,23] in a state of normal ventilation with positive end-expiratory pressure (PEEP) is $\leq 5 \mathrm{~cm} \mathrm{H}_{2} \mathrm{O}$. This period is known as an 'observation period' and varies from 30 minutes to 2 hours in duration. Upon successful completion of a SBT, the ventilator issues a directive stating that the patient is "ready for separation from ventilator". Prior to extubation, physicians must ensure that patients meet readiness criteria to proceed with extubation. With SmartCare ${ }^{\mathrm{TM}}$, clinicians titrate the fractional concentration of inspired oxygen $\left(\mathrm{FiO}_{2}\right)$ and PEEP. The automated algorithms may be applied during the day or during the day and at night.

SmartCare ${ }^{\mathrm{TM}}$ has been evaluated in physiologic studies and randomized controlled trials (RCTs). Similar to physician assessments using conventional pressure support, SmartCare $^{\mathrm{TM}}$ was demonstrated in two physiologic studies to be capable of evaluating patient's ability to breathe spontaneously [22], decrease work of breathing, and reduce periods of respiratory distress during weaning [23]. A prospective cohort study of 42 intubated critically-ill patients, demonstrated that SmartCare ${ }^{\mathrm{TM}}$ could support ventilation over prolonged time periods (up to 12 days) [24]. Moreover, the system recognized patient's readiness to undergo a SBT earlier than intensive care physicians [24]. In a preliminary RCT involving 144 patients conducted in 5 European centres, Lellouche and colleagues showed that, compared to usual care directed by protocols in most centres, SmartCare ${ }^{\mathrm{TM}}$ decreased the median duration of ventilation from 4 to 2 days $(p=0.02)$, total duration of ventilation ( 9 to 6.5 days, $\mathrm{p}=0.03$ ), median ICU length of stay ( 15.5 to 12.0 days, $p=0.02$ ) and nonsignif- 
icantly reduced the number of patients requiring prolonged ventilation ( $>21$ days) (15.7 vs $6.7 \%, \mathrm{p}=0.11$ ) [25]. Conversely, in a single centre RCT in Australia, comparing SmartCare ${ }^{\mathrm{Tu}}$ to usual care in 102 patients, Rose and coworkers did not demonstrate reductions in weaning time or complication rates [26]. Moreover, the generalizability of results from these regions to Canada where weaning is a collaborative effort, involving registered respiratory therapists (RRTs) and intensivists, is unknown.

\section{Objectives}

The primary objective of the multicentre pilot study comparing SmartCare ${ }^{\mathrm{TM}}$ [hereafter referred to as "Automated Weaning"] and "Protocolized Weaning" is to evaluate compliance with the weaning and sedation protocols among intubated patients requiring $>24 \mathrm{hrs}$ of invasive ventilation.

The secondary objectives of the multicentre pilot RCT are to evaluate clinician acceptance of the alternative weaning and sedation protocols using a Visual Analogue Scale daily, and to demonstrate the ability to recruit the desired patient population. In this manner, we will assess the feasibility of conducting a future, definitive weaning RCT in Canada.

\section{Methods}

Study Design

A pilot RCT is currently underway at 8 adult ICUs across Canada in collaboration with the Canadian Critical Care Trials Group. Ethics approval for the study was obtained from the Research Ethics Board (REB) at St Michael's hospital and the REBs of participating centres. Figure 1 provides an overview of the study.

\section{Run-in Phase}

Prior to initiating the pilot RCT, we conducted a "run-in phase". The run-in phase included two patients at each centre. While, the first patient was randomized to either Automated Weaning or Protocolized Weaning, the second patient was assigned to the alternative weaning strategy in

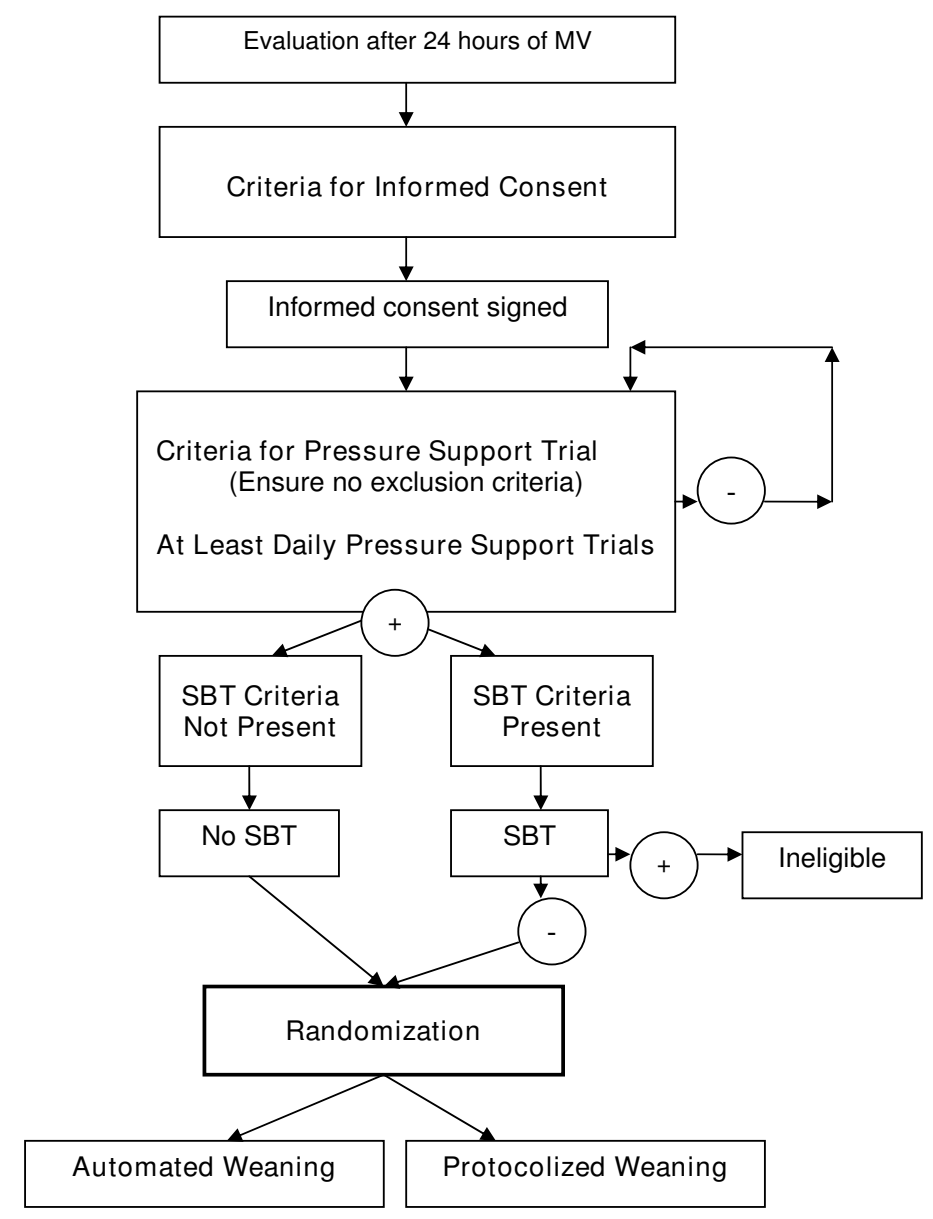

Figure I

Study Flow Diagram. 
a non-random manner. Upon completion of the two patients, a clinical evaluation committee reviewed the completed case report forms to assess (i) the ability of participating centres to screen and enroll patients, (ii) compliance with study procedures, and (iii) timeliness of data collection and management. Approval from the clinical evaluation committee enabled sites to proceed to enrolling patients in the pilot RCT.

\section{Patient Screening}

A dedicated research coordinator at each site screens patients for eligibility daily between 6:00 and 9:00 am at each site. We use a staged process to (i) identify potential study participants early in the weaning process and (ii) obtain consent for a Pressure Support Trials (PST). If patients fulfill the Criteria for Consent and have no exclusion criteria, a member of the investigative team approaches patients or their legal representatives for consent to (i) undergo a PST (once the Criteria for a Pressure Support Trial are attained) and a SBT (if criteria are met) and (ii) randomization depending on the outcome of the PST and SBT (see below).

\section{Criteria for Consent}

We developed criteria to enable early identification of potential weaning candidates and to obtain consent early in the weaning process. These criteria include:

1) invasive ventilation for $>24$ hours,

2) at least partial reversal of the condition precipitating invasive ventilation,

3) stabilization of "other" organ system failures (i.e. no worsening),

4) pulse oximetry oxygen saturation $\left(\mathrm{SpO}_{2}\right) \geq 90 \%$ with fractional concentration inspired oxygen $\left(\mathrm{FiO}_{2}\right) \leq$ $70 \%$,
5) $\mathrm{PEEP} \leq 12 \mathrm{~cm} \mathrm{H}_{2} \mathrm{O}$,
6) weight $>35 \mathrm{~kg}$
7) the absence of exclusion criteria

We exclude patients (i) less than 16 years of age, (ii) with a do not reintubate order documented on chart or anticipated withdrawal of life support, (iii) prolonged cardiac arrest with poor neurological prognosis, (iv) a prior episode of invasive ventilation exceeding $24 \mathrm{hrs}$ during the same hospital stay, (v) tracheostomy, (vi) pregnancy, (vii) known or suspected severe myopathy or neuropathy (i.e., Guillain-Barré syndrome) or quadriplegia, (viii) severe heart failure (grade 3 or 4 left ventricular function or New York Heart Association class 4 dyspnea).

\section{Criteria for Pressure Support Trial}

We consider consented patients, who meet the Criteria for Consent, to undergo a PST at least once daily when they meet the following criteria:

1) intubated patient on mechanical ventilation,

2) $\mathrm{SpO}_{2} \geq 90 \%$ with $\mathrm{FiO}_{2} \leq 50 \%$ and PEEP $\leq 10 \mathrm{~cm}$ $\mathrm{H}_{2} \mathrm{O}$,

3) no requirement for high dose vasopressors (i.e., no epinephrine or norepinephrine $>15 \mu \mathrm{g} / \mathrm{min}$ (or 0.2 $\mu \mathrm{g} / \mathrm{kg} / \mathrm{min}$ ) or equivalent dose vasopressin or phenylephrine),

4) motor component of the Glasgow Coma Scale score $\geq 4$ (withdraws to pain),

5) stable neurological status (no deterioration in the last $24 \mathrm{hrs}$, intact respiratory drive, and intracranial pressure $<20$ ),

6) patient not expected to be extubated on the day of study randomization,

7) no surgery or procedure requiring sedation planned in the next 48 hrs.

We reassess criteria for a PST at least once daily after consent is obtained.

\section{Detailed Study Methods}

Pressure Support Trials

PSTs are required to identify patients at the onset of the recovery phase when patients are first able to tolerate assisted ventilation. We adjust the level of pressure support provided to obtain a RR $\leq 35$ breaths/min during PSTs. The initial level of pressure support is set at $15 \mathrm{~cm}$ $\mathrm{H}_{2} \mathrm{O}$ for patients not already on this mode and at the current level of pressure support in patients already on pressure support. PSTs are at least 60 consecutive minutes and not longer than 120 minutes in duration. The maximal pressure support (above PEEP) is $22 \mathrm{~cm} \mathrm{H}_{2} \mathrm{O}$ and the minimum is $10 \mathrm{~cm} \mathrm{H}_{2} \mathrm{O}$. A PST can be stopped at any time for sustained hemodynamic or respiratory distress (heart rate $\leq 50$ or $\geq 140$ beats per minute or new significant dysrhythmias, systolic blood pressure $\leq 80 \mathrm{~mm} \mathrm{Hg}$ or $\geq 180$ $\mathrm{mm} \mathrm{Hg}$ or $\mathrm{RR}>40$ breaths/min).

A PST is considered successful if after 60 consecutive minutes without a change in the level of pressure support, the patient remains clinically stable with a RR less than or equal to 35 and greater than 10 breaths/min with no decrease in pulse oximetry saturations $\left(\mathrm{SpO}_{2}\right.$ remains $\geq$ $90 \%$ on an $\mathrm{FiO}_{2} \leq 50 \%$ with PEEP $\left.\leq 8 \mathrm{~cm} \mathrm{H} \mathrm{H}_{2} \mathrm{O}\right)$. Patients who fail a PST are returned to their previous ventilator set- 
tings or settings that restore respiratory comfort. We reassess these patients at least daily for criteria to undergo a PST. Patients who successfully complete a PST are assessed for a SBT. Patients who do not meet SBT criteria (i.e., are too early to undergo a SBT) are randomized upon successful completion of a PST.

\section{Spontaneous Breathing Trials}

Since patients who successfully complete a PST include those who do and do not require further weaning, we conduct an SBT with the goal of identifying patients who can tolerate pressure support but fail an SBT. These individuals are regarded as requiring further weaning. We consider patients with (i) partial or complete reversal of the cause of respiratory failure with $\mathrm{SpO}_{2} \geq 90 \%$ on an $\mathrm{FiO}_{2} \leq 0.4$ (or at baseline level in chronically hypoxemic patients) and PEEP $\leq 5 \mathrm{~cm} \mathrm{H}_{2} \mathrm{O}$, (ii) hemodynamic stability [off vasopressors or on low levels of vasopressors (i.e., levophed $\leq 7 \mu \mathrm{g} / \mathrm{min}$ or $\leq 0.1 \mu \mathrm{g} / \mathrm{kg} / \mathrm{min}$ ) or equivalent], (iii) absence of uncontrolled sepsis, and (iv) stable haemoglobin $>70 \mathrm{~g} / \mathrm{L}$ to undergo a SBT. We conduct SBTs of 30 to 120 minutes duration using either a T-piece with oxygen or continuous positive airway pressure (CPAP) $\leq 5 \mathrm{~cm}$ $\mathrm{H}_{2} \mathrm{O}$ or PSV of $5-7 \mathrm{~cm} \mathrm{H} \mathrm{H}_{2} \mathrm{O}$ (using a heated humidifier or alternatively, $10-12 \mathrm{~cm} \mathrm{H}_{2} \mathrm{O}$ with a heat and moisture exchanger) [27,30] with or without $5 \mathrm{~cm} \mathrm{H_{2 }} \mathrm{O}$ PEEP. Patients who successfully complete a SBT are considered for extubation (i.e., do not require further weaning). Conversely, patients who fail a SBT are randomized. We consider the presence of any one of the following: (i) RR > 35 breaths/min, (ii) clinical signs of respiratory distress (i.e., abdominal paradox), (iii) $\mathrm{SpO}_{2}<90 \%$ (or below baseline in chronically hypoxemic patients) with $\mathrm{FiO}_{2}>50 \%$, (iv) systolic blood pressure $\leq 80 \mathrm{mmHg}$ or $\geq 180 \mathrm{mmHg}$, (v) heart rate $\leq 50$ or $\geq 140$ beats/min or new significant dysrhythmias, (vi) severe agitation or diaphoresis, or (vii) Increased somnolence with elevated arterial pressure of carbon dioxide $\left(\mathrm{PaCO}_{2}\right)$ and $\mathrm{pH}<7.30$ to signify SBT failure. In summary, we randomize consented patients requiring pressure support of at least $10 \mathrm{~cm} \mathrm{H}_{2} \mathrm{O}$ who (i) successfully complete a PST, but DO NOT meet criteria to undergo a SBT (i.e., are too early to undergo a SBT) or (ii) who successfully complete a PST and fail a SBT.

\section{Study Randomization}

Patients undergo stratified randomization within centres based on the presence (or absence) of (i) a diagnosis of known or suspected COPD [31,32] or (ii) a central neurologic disorder, provided that a study ventilator is available. In the event that both diagnoses are present, we prioritize central neurologic disorders during stratification.

\section{Weaning Procedures}

Randomized patients are initiated on either the Automated Weaning or Protocolized Weaning algorithms until extubation criteria are achieved. All patients will be followed until successful extubation, ICU death, ICU discharge or until 90 days after randomization (deemed ventilator dependent).

\section{a) Ventilators}

We use the Evita XL ventilator (which includes SmartCare $^{\mathrm{TM}}$ ) or, alternatively, the Evita 2 dura or Evita 4 ventilators with a SmartCare ${ }^{\mathrm{TM}}$ ventilator upgrade in patients randomized to the Automated Weaning strategy. We equipped participating centres with a minimum of two of these ventilators. Comparable third generation ventilators (Evita 2 dura, Evita 4, Evita XL, Servo i, Servo 300, Puritan Bennett 840, Puritan Bennett 760, Avea or Galileo) are used in the Protocolized Weaning arm. We preferentially use Evita ventilators in the Protocolized Weaning arm if additional ventilators, when available.

\section{b) Humidification systems and ventilator circuits}

We clustered use of different forms of humidification to warm inspired air in the WEAN study to gain experience in the interaction of different forms of humidfication with the automated algorithm. We use heated humidifiers (MR850, Fisher \& Paykel; Auckland, New Zealand) in both study arms in 5 centres and heat and moisture exchangers at 3 centres, to gain experience with the interaction between humidification and the Automated Weaning system. We record changes from one humidification strategy to another in the event difficulties (secretion volume, alarms etc) on the data collection forms. We use either RT 110 or RT 240 (Evaqua $^{\mathrm{TM}}$ ) circuits in the WEAN study. Reusable circuits are not permitted.

\section{c) Ventilator strategies and alarms}

Regardless of the strategy to which the patient is randomized, the initial pressure support setting is similar to that used during the PST. In both groups, pressure support may increase or decrease during weaning according to patient needs or events (i.e., mucous plugging, anxiety). We present the details including initiation, titration and discontinuation) of the Automated Weaning and Protocolized Weaning strategies (in Additional file 1, Appendices 1 and 2). We set the maximum inspiratory pressure to $35 \mathrm{~cm} \mathrm{H}_{2} \mathrm{O}$ in the Automated Weaning arm.

\section{d) Criteria to suspend weaning protocols/return to an alternate mode of ventilation}

In both groups, patients are permitted to return to or remain on alternate modes of ventilation for: (i) surgery or invasive procedures requiring sedation, (ii) respiratory distress defined by a) sustained hypoxemia $\left(\mathrm{SpO}_{2}<90 \%\right)$ with $\mathrm{FiO}_{2}>60 \%$ and PEEP $>10 \mathrm{~cm} \mathrm{H}_{2} \mathrm{O}$ or hypercapnia with $\mathrm{pH}<7.30$ or clinical respiratory distress, b) repeated episodes ( $\geq 3$ episodes within 1 hour wherein an inspiratory pressure (pressure support + PEEP) of $35 \mathrm{cmH}_{2} \mathrm{O}$ is attained (despite suctioning, bronchodilation etc.), (iii) 
hemodynamic instability despite fluid boluses and the requirement for high dose vasopressors: norepinephrine > $15 \mu \mathrm{g} / \mathrm{min}(0.2 \mu \mathrm{g} / \mathrm{kg} / \mathrm{min})$ or equivalent, (iv) suspected myocardial ischemia based on electrocardiogram and/or elevated Troponin i, (v) neurologic deterioration with need to control $\mathrm{PaCO}_{2}$ (both groups) or alarm indicating "Central hypoventilation" (Automated Weaning), (vi) a requirement for increased sedation resulting in $R R<10$ breaths $/ \mathrm{min}$. Patients meeting a criterion, are reassessed at least daily with PSTs to identify the earliest time when weaning can be resumed according to the assigned treatment. However, the pre-randomization requirement to undergo a SBT (if criteria are present) is not required at this time point.

\section{e) Reintubation and implications for ventilator management} In the Automated Weaning arm, a ventilator capable of delivering SmartCare ${ }^{\mathrm{TM}}$ is kept in the patient's room following extubation until the patient is deemed successfully extubated [off non-invasive (NIV) or invasive positive pressure ventilation for 48 consecutive hours]. Patients remain on the assigned strategy until ICU discharge, ICU death, successful extubation or until day 90 following randomization. Patients requiring reintubation in the Automated Weaning arm within 48 hours of extubation will be weaned using SmartCare ${ }^{\mathrm{TM}}$ as soon as possible (i.e., upon successful completion of a PST). All patients that require reintubation after successful extubation will be ventilated according to usual practice.

\section{f) Sedation titration}

We developed a sedation guide to guide sedation administration and limit performance bias during weaning. Critical care nurses titrate sedation to achieve either a Sedation Agitation Scale (SAS) [33] score of 3 to 4 (see Additional file 1, Appendix 3) or a Richmond Agitation Scale Score (RASS) [34] of -3 to 0 [35]. Sedation titration is not mandatory in patients meeting criteria to return to or remain on an alternate mode of ventilation.

\section{g) Other considerations}

We developed a PEEP/ $/ \mathrm{FiO}_{2}$ chart to guide their titration during weaning (see Additional file 1, Appendix 4). Use of the $\mathrm{PEEP} / \mathrm{FiO}_{2}$ chart is not mandatory for patients meeting criteria to return to or remain on an alternate mode of ventilation.

Additional important considerations in developing the WEAN Study protocol include (i) the initiation and use of NIV following extubation [36,37], (ii) reintubation and reinitiation of weaning [38] and (iii) performance of a tracheostomy (Additional file 1, Appendix 5). For patients randomized to Automated Weaning, the data entered to initiate the system must be re-entered following a tracheostomy or change in humidification device prior to reconnection.

\section{Study Outcomes}

The primary outcome of the WEAN pilot study is compliance with the weaning and sedation protocols. Secondary outcomes include (i) daytime clinician (nurse; RRT and physician) acceptance of the sedation and weaning protocols, respectively, (ii) time to successful extubation defined as the time from randomization to unsupported (no requirement for NIV or invasive ventilation), spontaneous breathing for $\geq 48$ hours after extubation (or disconnection with a tracheostomy), (iii) time to completion of a successful SBT, (iv) total duration of mechanical ventilation (time from intubation to termination of ventilation), (vi) ICU and hospital length of stay, (vii) ICU and hospital mortality, and the proportion of patients (viii) developing nosocomial pneumonia [39], (ix) with weaning (self-extubation, tracheostomy, reintubation and prolonged mechanical ventilation $>21$ days) or ICU (myocardial infarction and pneumothoraces) complications, and (x) requiring NIV. Any NIV use is considered clinically relevant.

\section{Data Collection}

We collect data at ICU admission, study inclusion and daily thereafter. Whereas protocol violations (non compliance) in the Automated Weaning arm include return to/remain on an alternate mode of mechanical ventilation in the absence of meeting criteria and any unauthorized interruptions (cessations, manual increases/decreases) in the automated protocol, violations in the Protocolized Weaning group include unauthorized use of modes other than pressure support (i.e., assist control) without criteria to return to or remain on an alternate mode of mechanical ventilation. We tabulate a daily score reflecting the number of SBTs conducted divided by the number of required SBT assessments in which all criteria were met in the Protocolized Weaning group. Sedation protocol compliance is assessed by the percentage of daily SAS scores $<$ 2 or $>5$ (or alternatively, RASS scores $<-4$ or $>+1$ ) in both arms. We also evaluate compliance with the PEEP/FiO chart in both groups. RRT and physician acceptance of the weaning protocols and critical care nurse acceptance of the sedation protocol is assessed daily using Likert [40] scales [ranging from 0 highly unacceptable (extremely difficult to use) to 10 highly acceptable (extremely easy to use)].

\section{Statistical Analyses}

Descriptive statistics including means, standard deviations, medians, interquartile ranges and frequency distributions will be used to summarize the data. For univariate analyses, we will use the Chi-square test (alternatively, Fisher's exact test when the expected value is $\leq 5$ ) and Student's t-test (alternatively, the Mann-Whitney U-test, if normality assumptions are not satisfied) for binary and continuous outcomes, respectively. We will evaluate the percentage of (i) hours off-protocol and (ii) daily SAS 
scores $<2$ or $>5$ (or RASS equivalent) by treatment group. Compliance will be considered acceptable if $\geq 75 \%$ [that is; protocol violations (off protocol hours without meeting criteria to return to/remain on an alternate mode of mechanical ventilation) or SAS scores $<2$ or $>5$ (equivalent RASS $-4<$ or $>+1$ ) occur $<25 \%$ of the time]. SBT compliance will be considered acceptable if $\geq 75 \%$ of SBT opportunities are realized. We will compare average Likert scale scores based on clinician group and the weaning strategy utilized using Analysis of Variance (ANOVA). We will compare time to successful extubation and death between groups using time-to-event analysis with censoring of deaths and application of the log-rank test. We will consider p-values $\leq 0.05$ to be statistically significant.

\section{Sample Size}

Estimates are not available to allow precise sample size estimation of the primary outcome for the multicentre pilot RCT. To ensure that the study protocols are easy to follow before engaging in a definitive weaning RCT, we estimate that a total of 90 patients (ideally approximately 11-12 patients per site) are required to assess protocol compliance. To ensure that all centres gain some experience with both protocols, we set a maximum site enrolment of 35 patients.

\section{Discussion}

Life support technology interventions account for 5-10\% of acute care bed occupancy and 34\% of hospital budgets [41]. Current demands are expected to escalate in the future as the middle sector of our population ages [42]. Since up to $40 \%$ of the time on mechanical ventilation is related to weaning, Automated Weaning holds promise as a strategy to reduce ICU length of stay and the total time spent on mechanical ventilation by reducing weaning time, and weaning and ICU-related complications. More importantly, Automated Weaning may reduce the burden of illness related to protracted invasive ventilation and improve patient-important outcomes [43]. A key benefit of SmartCare ${ }^{\mathrm{TM}}$ is that weaning is unencumbered by limited clinician availability in the busy ICU setting. Prior to conducting a full scale RCT comparing the effect of the alternative weaning strategies on important clinical outcomes, we designed a feasibility RCT to assess clinician compliance with and acceptance of the detailed weaning and sedation protocols [44].

In the absence of evidence regarding the current 'standard of care in weaning' in Canada, we developed, tested and administered a questionnaire to RRT and physician leaders using rigorous survey methodology [45] to identify key aspects of weaning (use of protocols, daily screening, conduct of SBTs, preferred methods of support) at Canadian teaching hospitals. In this manner, we identified that daily screening and pressure support were common features of weaning and that most centres conduct SBTs using one of three strategies [46]. The results of the National Weaning Survey informed the design of the paper-based weaning protocol (control arm) in the WEAN Study.

Prior to initiating the multicentre WEAN Study, we conducted a run-in phase study involving two patients per centre. We randomized the first participant at each centre to either Automated or Protocolized Weaning and assigned the second patient to the alternate weaning strategy. We conducted the run in phase to ensure that participating centres could implement the detailed weaning and sedation protocols and complete the case report forms. Mechanical ventilation studies require detailed daily data collection and for protocols to be operationalized continuously. Following review of run in phase study procedures, a clinical evaluation committee approved sites to proceed with enrollment in the WEAN pilot RCT.

\section{Conclusion}

The WEAN pilot study was designed to evaluate clinician compliance with and acceptance of the proposed weaning and sedation protocols. In addition, we will ascertain whether centres can recruit the desired patient population. Strengths of the WEAN Study include the use of central randomization, allocation concealment, stratification (to ensure equal distribution of conditions that may prolong ventilation) and the use of protocols in both arms to limit treatment and performance bias. To this end, both treatment arms use pressure support and include opportunities to undergo SBTs. Moreover, they share a common $\mathrm{PEEP} / \mathrm{FiO}_{2}$ chart, sedation protocol, extubation and reintubation criteria, and criteria for NIV use for post-extubation respiratory failure. The major threat to the validity of the pilot RCT is that it is, out of necessity, unblinded. To this end, we developed detailed weaning and sedation protocols to limit potential sources of bias and standardize weaning and sedation administration in both study arms and across participating centres. While we can not blind clinicians, patients and data collectors, we will blind the data analyst to treatment group assignment until the planned statistical analyses are completed. As the first multicentre weaning RCT in Canada, the WEAN Study seeks not only to determine the feasibility of conducting a large scale future weaning trial, but to establish a collaborative network of ICU clinicians dedicated to advancing the science of weaning.

\section{Abbreviations}

VAP: ventilator associated pneumonia; ICU: Intensive Care Unit; SBT: Spontaneous Breathing Trial; RR: Respiratory rate; $\mathrm{V}_{\mathrm{T}}$ : Tidal volume; $\mathbf{E T C O}_{2}$ : end tidal carbon dioxide; COPD: Chronic Obstructive Pulmonary Disease; PEEP: Positive End-Expiratory Pressure; $\mathrm{FiO}_{2}$ : Fractional concentration of inspired oxygen; RCT: randomized controlled trial; $\mathrm{SpO}_{2}$ : Pulse oximetry oxygen saturation; CPAP: continuous positive airway pressure; PST: Pressure 
Support Trial; NIV: noninvasive ventilation; SAS: sedation agitation scale; RASS: Richmond Agitation Scale Score; $\mathrm{PaO}_{2} / \mathrm{FiO}_{2}$ : Arterial partial pressure oxygen/Fractional concentration of inspired oxygen ratio; RRT: Registered Respiratory Therapist; ASB: automatic spontaneous breathing; HME: heat and moisture exchanger; $\mathbf{H H}$ : heated humidification; ATC: automatic tube compensation; LOC: level of consciousness.

\section{Competing interests}

Drs Burns and Lellouche hold a travel bursary from Draeger Medical Inc. (Canada) to conduct site visits for the WEAN Study. The WEAN Study is an investigator-initiated, peer-review funded trial. No other author(s) has a financial relationship with a commercial entity that has an interest in the subject of the manuscript.

\section{Authors' contributions}

$\mathrm{KB}, \mathrm{MM}, \mathrm{ML}, \mathrm{SK}$, and FL contributed to the conception and design of the WEAN study, drafted and revised the manuscript for important intellectual content.

$\mathrm{KB}, \mathrm{MM}, \mathrm{ML}, \mathrm{SK}$, and FL approved the final version of the manuscript.

\section{Additional material}

\section{Additional file 1}

Appendices 1-5.

Click here for file

[http://www.biomedcentral.com/content/supplementary/17456215-10-81-S1.doc]

\section{Acknowledgements}

We wish to thank the members of the Canadian Critical Care Trials Group and the Critical Care Interest Group (McMaster University, Hamilton, Ontario) for their assistance in developing and testing the questionnaire. Dr. Burns holds a Clinician Scientist award from the Canadian Institutes of Health Research. Dr. Lellouche holds a FRSQ (Fonds de la Recherche en Sante du Quebec) Chercheur-Clinicien Junior grant.

Sources of Funding: The WEAN Study is funded with grants from the Physician Services Incorporated Foundation, Ontario Thoracic Society, a Connaught New Staff Matching Grant, Hopital Laval Research Fund and Le Reseau en Sante Respiratoire du Fonds de la Recherche en Sante du Quebec. The funding sources had not role in the study design, data collection, analysis, interpretation or manuscript preparation.

\section{References}

I. Esteban A, Alia I, Ibanez J, Benito S, Tobin MJ: Modes of mechanical ventilation and weaning. A national survey of Spanish hospitals. The Spanish Lung Failure Collaborative Group. Chest 1994, 106(4): 1 188-93.

2. Esteban A, Anzueto A, Frutos F, et al.: Characteristics and outcomes in adult patients receiving mechanical ventilation: a 28-day international study. JAMA 2002, 287(3):345-55.

3. Pingleton SK: Complications of acute respiratory failure. $A m$ Rev Respir Dis 1988, 137:1463-93.
4. Niederman MS, Ferranti RD, Ziegler A, et al.: Respiratory infection complicating long-term tracheostomy: the implication of persistent gram negative trachobronchial colonization. Chest 1984, 85:39-44.

5. Heyland DK, Cook DJ, Griffith L, et al: The attributable morbidity and mortality of venetilator associated pneumonia in the critically ill patient. Am J Respir Crit Care Med 1999, I 59: I249-56.

6. Dasta JF, McLaughlin TP, Mody SH, Tak Piech C: Daily cost of an intensive care unit day: the contribution of mechanical ventilation. Crit Care Med 2005, 33: I266-7I.

7. Maclntyre NR, Cook DJ, Ely EW Jr, et al.: Evidence-based guidelines for weaning and discontinuing ventilator support. A collective task force facilitated by the American College of Chest Physicians, the American Association for Respiratory Care; and the American College of Critical Care Medicine. Chest 200I, I 20(6 Suppl):375-95S.

8. Ely EW, Baker AM, Dunagan DP, et al.: Effect of the duration of mechanical ventilation on identifying patients capable of breathing spontaneously. N Engl J Med 1996, 335: 1864-9.

9. Kollef $\mathrm{MH}$, Shapiro SD, Silver $\mathrm{P}$, et al:: A randomized, controlled trial of protocol-directed versus physician-directed weaning from mechanical ventilation. Crit Care Med 1997, 25:567-74.

10. Marelich GP, Murin S, Battistella F, et al.: Protocol weaning of mechanical ventilation in medical and surgical patients by respiratory care practitioners and nurses. Effect on weaning time and incidence of ventilator associated pneumonia. Chest 2000, II 8:459-67.

II. Esteban A, Alia I, Gordo F, et al:: Extubation outcome after spontaneous breathing trials with t-tube or pressure support ventilation. Am J Respir Crit Care Med 1997, 156:459-65.

12. Esteban A, Alia I, Tobin MJ: Effect of spontaneous breathing trial duration on outcome of attempts to discontinue mechanical ventilation. Am J Respir Crit Care Med 1999, 159:512-8.

13. Perren A, Domenighetti G, Mauri S, Genini F, Vizzardi N: Protocoldirected weaning from mechanical ventilation; clinical outcome in patients randomized for a 30-minute and 120 minute trial with pressure support. Intensive Care Med 2002, 28:1058-63.

14. Brochard L, Rauss A, Benito S, et al.: Comparison of three methods of gradual withdrawal from ventilatory support during weaning from mechanical ventilation. Am J Respir Crit Care Med 1994, 150:896-903.

15. Esteban A, Frutos F, Tobin MJ, et al.: A comparison of four methods of weaning patients from mechanical ventilation. $N \mathrm{Engl}$ I Med 1995, 332:345-50.

16. Esen F, Denkel T, Telci L, et al.: Comparison of pressure support ventilation and intermittent mandatory ventilation during weaning in patients with acute respiratory failure. Adv Exp Med Biol 1992, 317:37|-6.

17. Ely EW, Bennett PA, Bowton DL, Murphy SM, Florance AM, Haponik EF: Large scale implementation of a respiratory therapistdriven protocol for ventilator weaning. Am J Respir Crit Care Med 1999, I59(2):439-46.

18. Vitacca M, Clini E, Porta R, Ambrosino N: Preliminary results on nursing workload in a dedicated weaning center. Intensive Care Med 2000, 26(6):796-9.

19. Burns K, Lellouche F, Lessard M: Automating the weaning process with advanced closed-loop systems. Intensive Care Med 2008, 34( ( 0): 1757-65. Epub2008 Jun 3.

20. Dojat M, Brochard L, Lemaire F, Harf A: A knowledge-based system for assisted ventilation of patients in intensive care units. Int J Clin Monit Comput 1992, 9(4):239-50.

21. Dojat M, Brochard L: Knowledge-based systems for automatic ventilatory management. Respir Care Clin N Am 200I, 7(3):379-96. viii.

22. Dojat M, Harf A, Touchard D, Laforest M, Lemaire F, Brochard L: Evaluation of a knowledge-based system providing ventilatory management and decision for extubation. Am J Respir Crit Care Med 1996, 153(3):997-1004.

23. Dojat M, Harf A, Touchard D, Lemaire F, Brochard L: Clinical evaluation of a computer-controlled pressure support mode. Am J Respir Crit Care Med 2000, I6I(4 Pt I): II6I-6.

24. Bouadma L, Lellouche F, Cabello B, et al.: Use of an automated control system to adapt the level of pressure support and manage weaning. Intensive Care Med 2002, 28(I):S23. 
25. Lellouche F, Mancebo J, Jolliet RJP, et al.: Computer-driven ventilation reduces duration of weaning: a multicenter randomized controlled study. Intensive Care Med 2004, 30:S69.

26. Rose L, Presneill J, Johnston L, Cade JF: A randomized, controlled trial of conventional versus automated weaning from mechanical ventilation using SmartCare/PS. Intensive Care Med 2008, 34(1 0): I788-95. Epub2008 Jun 25.

27. Jaber S, Pigeot J, Fodil R, Maggiore S, Harf A, Isabey D, Brochard L: Long-term Effects of Different Humidification Systems on Endotracheal Tube Patency. Anesthesiology 2004, I00:782-8.

28. Boots RL, George N, Faoagali JL, Druery J, Dean K, Heller RF: Double-heater-wire circuits and heat-and-moisture exchangers and the risk of ventilator-associated pneumonia. Crit Care Med 34:687-93.

29. Girault C, Breton L, Richard JC, Tamion F, Vandelet P, Aboab J, Leroy J, Bonmarchand G: Mechanical effects of airway humidification devices in difficult to wean patients. Crit Care Med 2003, 3I:I306-II.

30. Iotti GA, Olivei MC, Braschi A: Mechanical effects of heat-moisture exchangers in ventilated patients. Crit Care 1999, 3:R77-82. Epbul999 Sept 23.

31. Pauwels R, Buist S, Calverly P, et al.: Global strategy for the diagnosis, management and prevention of chronic obstructive pulmonary disease. NHLBI/WHO Global Initiative for Chronic Obstuctive Lung Disease (GOLD) Workshop Summary. Am J Respir Crit Care Med 200I, I 63:1256-76.

32. Bourbeau J, Nault D, Borycki E, editors: Assessment of COPD. In Comprehensive Management of Chronic Obstructive Pulmonary Disease Philadelphia: BC Decker; 2002.

33. Riker RR, Picard JT, Fraser GL: Prospective evaluation of the Sedation-Agitation Scale for adult critically ill patients. Crit Care Med 1999, 27(7): I325-9.

34. Sessler CN, Gosnell MS, Grap MJ, Brophy GM, O'Neal PV, Keane KA, Tesoro EP, Elswick RK: The Richmond Agitation-Sedation Scale: validity and reliability in adult intensive care unit patients. Am J Respir Crit Care Med 2002, I 66 (I 0): 1338-44.

35. Brook AD, Ahrens TS, Schaiff $R$, et al.: Effect of a nursing-implemented sedation protocol on the duration of mechanical ventilation. Crit Care Med 1999, 27:2609-I5.

36. Keenan SP, Powers C, McCormack DG, Block G: Noninvasive Positive-Pressure Ventilation for Postextubation Respiratory Distress. JAMA 2002, 287(24):3238-3244.

37. Esteban A, Frutos-Vivar F, Ferguson ND, et al.: Noninvasive positive-pressure ventilation for respiratory failure after extubation. N Engl J Med 2004, 350(24):2452-60.

38. Brochard L, Mancebo J, Wysocki M, et al.: Noninvasive ventilation for acute exacerbations of chronic obstructive pulmonary disease. $N$ Engl J Med I995, 333(I 3):8|7-22.

39. Pugin J, Auckenthaler R, Mili N, et al.: Diagnosis of ventilator-associated pneumonia by bacteriologic analysis of bronchosciopic and nonbronchoscopic "blind" bronchoalveolar lavage. Am Rev Respir Dis 1991, I43: I I21-9.

40. Elder JP, Artz LM, Beaudin P, et al: Multivariate evaluation of health attitudes and behaviors: development and validation of a method for health promotion research. Prev Med 1985, | 4:34-54.

4I. Multz AS, Chalfin DG, Samson IM, et al.: A "closed" medical intensive care unit improves resource utilization when compared to an "open" MICU. Am J Respir Crit Care Med 1998, I 57:|468-73.

42. Needham D, Bronskill SE, Calinawan JR, et al.: Projected incidence of mechanical ventilation in Ontario to 2026: Preparing for the aging baby boomers. Crit Care Med 2005, 33:574-9.

43. Guyatt GH, Montori VM, Deveraux PJ, et al:: Patients at the center: In our practice and in our use of language (Editorial). ACP Journal Club 2004, I 40:AII.

44. Arnold DM, Burns KE, Adhikari NK, Kho ME, Meade MO, Cook DJ: The design and interpretation of pilot trials in clinical research in critical care. Crit Care Med 2009, I(Suppl):S69-74.

45. Burns KE, Duffett M, Kho ME, Meade MO, Adhikari NK, Sinuff T, Cook DJ, ACCADEMY Group: A guide for the design and conduct of self-administered surveys of clinicians. CMAJ 2008, I 79(3):245-52.

46. Burns KEA, Lellouche F, Loisel F, Slutsky AS, Meret A, Smith O, Saskin R, Meade MO, for the Canadian Critical Care Trials Group: Weaning Critically III Adults from Invasive Mechanical Ventilation: A National Survey. in press.
Publish with Biomed Central and every scientist can read your work free of charge

"BioMed Central will be the most significant development for disseminating the results of biomedical research in our lifetime. "

Sir Paul Nurse, Cancer Research UK

Your research papers will be:

- available free of charge to the entire biomedical community

- peer reviewed and published immediately upon acceptance

- cited in PubMed and archived on PubMed Central

- yours - you keep the copyright 